\title{
A survey: the role of the internet of things in the development of education
}

\author{
Ridhab Sami Abd-Ali, Sarah Abbas Radhi, Zaid Ibrahim Rasool \\ Department of Computer Engineering Techniques, Al-Mustaqbal University College, Iraq
}

\begin{tabular}{l}
\hline \hline Article Info \\
\hline Article history: \\
Received Jul 5, 2019 \\
Revised Jan 14, 2020 \\
Accepted Jan 28, 2020 \\
\hline
\end{tabular}

\section{Keywords:}

Digital campus

Internet of things

Smart class

Smart laboratories

\begin{abstract}
There is a demand to change the contents and activities, and adapt the methods for higher education institutions, especially, universities to let researchers and educational act more efficiently in a digital context. A welldesigned campus that combines technology is basic for developing digital university through facilities for learning, teaching, and research, enhancing the student trials, and supplying convenient settings. Within digital universities, technology can improve security, reduce costs, and offer devices for faculty, scholars, academics, and students. These advantages give more attention to university processes and evolutions, the experience of researchers and students. In this research, we have done a study on the Internet of things and its role in the development of education through the review of a group of previous research. Also, we have studied the smart class and its components and its difference with the traditional classes. Then we have displayed the smart laboratories and its applications. At the end of the research, the great importance of Internet of Things in universities and its importance to the teacher and the student was concluded by learning faster and developing and improving the educational process.
\end{abstract}

Copyright $@ 2020$ Institute of Advanced Engineering and Science. All rights reserved.

\section{Corresponding Author:}

Ridhab Sami Abd-Ali,

Department of Computer Engineering Techniques,

Al-Mustaqbal University College, Iraq.

Email: RidhabSami@mustaqbal-college.edu.iq

\section{INTRODUCTION}

Kevin Ashton is the first to use the Internet of Things (IoT) in 1999. The IoT defined by the researchers in many methods like the Internet of People, Internet of Anything, Internet of Everything, Internet of Marks, Internet of Data, and the Internet of Services [1, 2]. The Internet of Things (IoT) is an international network which combines things, and materials to the Internet support to interact or communicate with the environment [3,4]. The basic concept of the Internet of Things (IoT) is the pervasive existence in a variety of objects or things [5]. Thus, the IoT objects is much wider, indication to physical things, for example, people, cargos, and products that can be determined by different type of devices such as sensors, Radio-Frequency IDentification (RFID) tags, actuators, mobile phones, smart cards, GPS devices, and so on [6]. The objects can react with others and collaborate with their neighbors to achieve participating goals [7]. After reviewing many studies, we found several common problems in education systems, including students who live in remote areas where transportation is limited or students who have health disabilities cannot attend to the campus. Sometimes there is difficulty in assessing students 'performance when performing laboratory experiments accurately in terms of calculating the number of attempted times and the time taken to implement them [8]. Students who are unable to attend campus as a result of a particular circumstance need to accurately compensate for their missed scientific lectures [9]. The devices (lighting, air conditioning, display screens, laboratory equipment, etc.) that are working continuously on the university campus without the need for them, will lead to consuming more electrical energy. 
Documentation of the student's absence. After researching and discussing the above- mentioned problems, the following solutions were found: Documenting lectures electronically through the use of cameras and microphone and uploading them to the system helps those who live in remote areas or people with health disabilities to receive lectures and information remotely in their place [10], as well as for laboratory experiments when the system provides the ability to conduct experiments digitally, remotely and in a manner equivalent to actual experiments. Connecting all laboratory devices to the system helps the instructor to evaluate students accurately by calculating the number of times the student attempts to correctly implement the experiment [11]. The use of a sensing system within the educational unit, which determines the places and times of the presence of teaching staff and students within the classrooms and scientific laboratories to operate the necessary equipment at the time of need, which leads to the rationalization of electricity consumption. There is the ability to make the API monitoring devices to be an Internet of Things device by converting the monitoring device to a remote sensor, the sensors' data is stored using a cloud web server so that this information is used in the educational system [12]. Each student has its card ID that has several uses, including documenting students 'attendance in the classroom by reading each student's ID.

\section{IOT IN EDUCATION}

A formal definition of the Internet of Things is: "The Internet of Things is an integrated part of the Future Internet and could be defined as a dynamic global network infrastructure with self-configuring capabilities based on standard and interoperable communication protocols where physical and virtual things have identities, physical attributes, and virtual personalities and use intelligent interfaces, and are seamlessly integrated into the information network" [13].

Technology in learning has represented an essential role in linking and learning students. IoT has a significant effect on the learning field [14]. IoT should not only replace the conventional education methods has merely also brought changes in the infrastructure of learning institutions [15, 16]. Because of IoT worth as a technological center to enhance academic support and as a matter of course to teach basic ideas of computer science, the term Internet of Things in learning is included two faceted [17, 18], as shown in Figure 1.

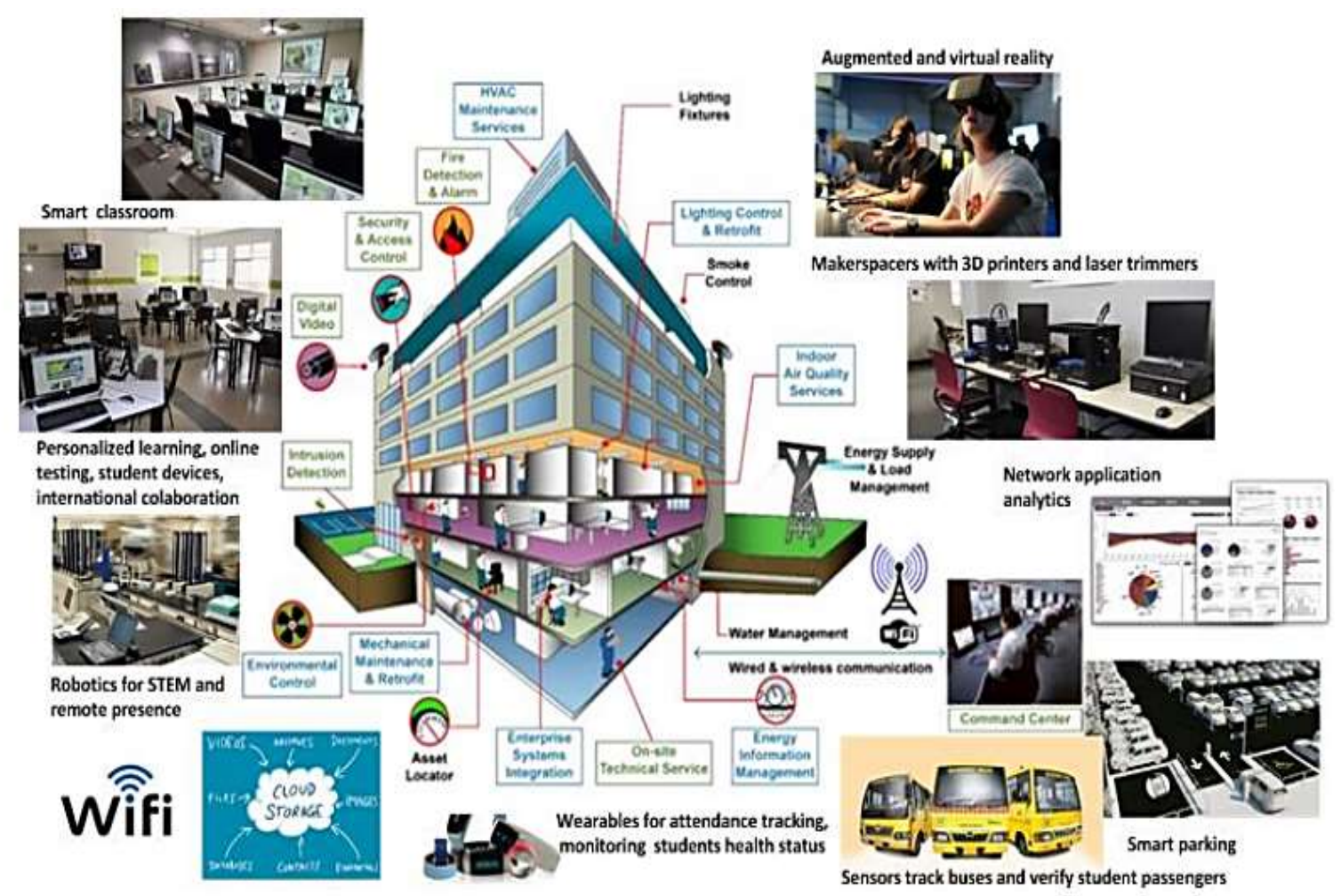

Figure 1. IoT educational environment [19] 
The internet of things environment contributes to learning new languages for students through the use of images, objects and videos in the classroom and this contributes to adding new cultures to students [20]. The Learner can access resources through using their devices including mobile phones, laptop, and tablets. So they can contact peers to share information, upload assignment and take tests that will lead to creating a dynamic learning environment [21]. The learning process is automated through using LMS software, by recording data from learners, tracking courses and managing reports [1, 22].

The learning section is also more affectionate as universities and schools make the use of connected devices broadly. For example, the using of Quick Response (QR) codes in educational textbooks. Assignments, Feedback, and other knowledge resources become easily available for students when they scan their QR codes by their smartphones [23]. Another example that the university departments can use the IoT devices to take automatic attendance by using the student ID cards, track equipment, and monitor security systems and lighting [24, 25]. Internet of things effects on the teaching profession and its system will be drastically causing differences in time of future expected college's campus support, and each process of using various IoT things will be related to instructional classrooms and its physical conditions [26].

The IoT is performing to change every part of the community at any time in the near future. Higher learning organization in common, and universities can work through correction and direct the development of the IoT technologies, market models, standards, and leaders of the IoT allowed economy of the future. For example, university trainers of computer science and engineering are directing IoT labs for the development of IoT technologies [27]. In addition, Information College can teach how to influence the sizes of IoT data, with TIPPSS. they can operate with business colleges to set and produce IoT ways to create new business models, Medical colleges, can enable the Internet of Medical Things as well as, Law academies can learn IoT manners, specificity, and policy.

\section{LITERATURE REVIEW}

In education systems, the Internet has rooted itself deeply. The internet of things (IoT), which is a new technology, is expected to make more important changes in the education sector. Many IoT devices can be utilized in education including, digital highlighters and Interactive boards. In the learning experience, the text is digitally transferred to smartphones with the assistance of digital scanners. Students can interact with educators, peers, and experts across the world, while they are sitting in their classroom by using these devices $[9,10]$.

In [11], the authors concentrate on IoT services utilization within the LMS. By IoT facilities, a significantly enhanced future LMS framework was proposed by the authors. This framework shows how several currently provided services in the existing learning management system will be changed after they are merged with IoT services and connecting them with devices and models of IoT. Also by integrating the IoT with the LMS some new services will be realized. In [25], a new paradigm introduced called the "Smart ICampus" that used in the universities where e-Learning is used. Other smart settings such as "Smart Classroom" and "Smart Lab" has been provided. Real-time data collected and uploaded by active Classrooms for future use. In the "Smart Notes Sharing" article any person connected to the network can share all the classroom notes by providing a smart device that can give real-time data to the e-Learning application. In addition, the smart classroom allows the students to learn more attractive with real-time information by providing attached sensors with objects when the students get near to learn about objects. According to [28], the Internet of Everything (IoE) discussed as a network of data, things, people, and processes. The term IoE does not focus only on IoT that is the composition of physical objects, but it also continues capabilities such as regard-awareness and raise power processing to millions of related people and objects.

Knowledge in a collaborative environment has been represented through the introduction of agent-based architectures. By using agents as specialized entities that are similar to traditional programs of the computer but differ by their operating ability on their own and autonomy with no guidance. Entities of solving problems can be running continuously and adjust their behavior according to perceiving environment changes. They control their actions and internal state and keep the path and learning what to do in a particular status by focus their goals and fulfill them through taking proactive initiatives. In order to create a Multi-Agent System (MAS), smart agents are installed within IoT devices to adaptively support activities of student learning by promoting real-time collaboration among learners/tutors and allowing tutors to take real-time actions to evidence/adjust the learning path of a group of students [29, 30].

The paper "Interaction System Based on Internet of Things as Support for Education," it continued said that IoT could provide a motive and could allow learners to be spirited. IoT, also enables lecturers to teach learners according to their experience, in a similar way, Teachers can take the necessary materials to accommodate learners. Learners also learn at their pace according to their abilities, so A one-size-fits-all 
program does not limit students. The organizers of the related article conducted an empirical validation that produced evidence that IoT could improve the student's education issues [31].

In [26], the goal of the study is to find out the circumstances of Internet things in higher education and how to maximize their profits and decrease the risks connected with them, so it is important to make more efforts to release the full potential of Internet systems and techniques things. Accordingly, this article performs a comparison on the result of Internet objects on higher education, especially in universities.

The Internet of things can allow interaction with physical space for communication or learning purposes. "Physical spaces in the classroom can be used in the classroom in an Internet technology way to monitor the teaching activity and contact the connected data recorder to participate in the application of the e-learning platform. The traditional classroom will be effectively converted into an intelligent classroom, and then effectively synchronizes with the application of e-learning [32].

\section{SMART CLASSROOMS}

Usually, in the traditional classroom, their activities do not record in any form, since they contain only display tools such as Blackboard and projector connected to the PC [33]. The blackboard became less common in used according to the use of new alternatives such as a whiteboard, interactive whiteboards, and flipcharts. Another classroom may also contain charts, TVs, books, maps, pencils, LCD projectors which is used to display images and information from a computer [34]. So by using the enhanced device to collect the learning and teaching activity in order to be recorded the classroom will be a smart classroom. These recorded activities help all students in any way even students who do not know those topics of subjects [35], as shown in Figure 2.

Objects controlled with IoT are equipped in a smart classroom to provide remotely functions. These functions include setting the classroom before the time of the lecture. The lecturer able to set the: lighting, the overhead projector and the temperature of the room before the lecture that will allow saving energy and time. In order to control this equipment, they must have the ability to receive orders for starting a certain action [36, 37].

With the help of IoT the data will be collected from the classroom, so that it's not only about presenting information and collecting the interactions form students. By doing this, these data can be stored for future use. A smart e-learning application can be used by uploading these data in the required format. The outsiders of the classroom can reach that information by using this application. So those lessons can learn anybody even if it was outside the classroom [26, 38].

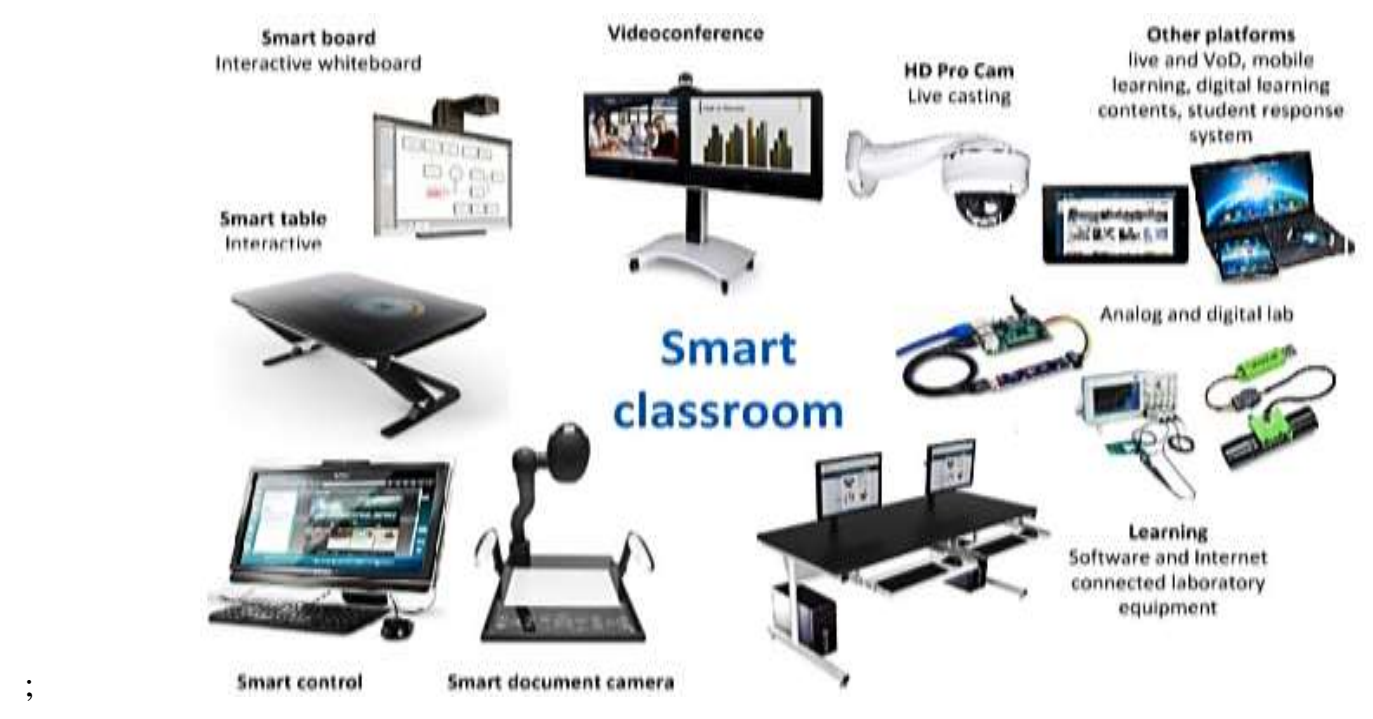

Figure 2. Smart classroom [24]

\section{SMART LABORATORIES}

In laboratories, IoT devices can be used in different ways. Where interactive experiments and simulations can be performed remotely by connecting many lab machines such as (microscope, chemical reactor, oscilloscope, Bunsen burner,...) with IoT devices. That will allow students to remotely control and 
access the IoT devices over the Learning Management System (LMS) [39]. For performing an experiment remotely, students can $\log$ in to his/her account to perform a specific experiment that he wants after selecting the required lab. Students can use IoT module to gather the data required for an experiment if external data are required in the experiment then save it to the profile of the experiment as shown in Figure 3 [40].

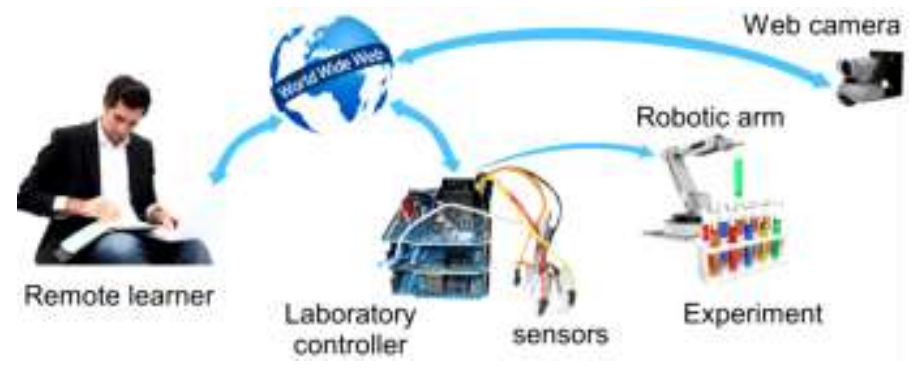

Figure 3. Remote experimentation system [8]

For each activity and experiment, the distribution of grades and assessment rules is stored with the help of IoT. The performance of students will be monitor by LMS via IoT modules and the grade will be automatically given for them after finishing the activity or experiment. The time required for students to perform each task completely, the number of errors and the number of attempts for each task will be analyzed by IoT [41]. By integrating the sensors with the IoT module, these parameters will be calculated. The students can record and save necessary readings on the LMS through his/her assessment profile through connecting the place near the activity or the experiment to monitor the students. As shown in Figure 4 [42].

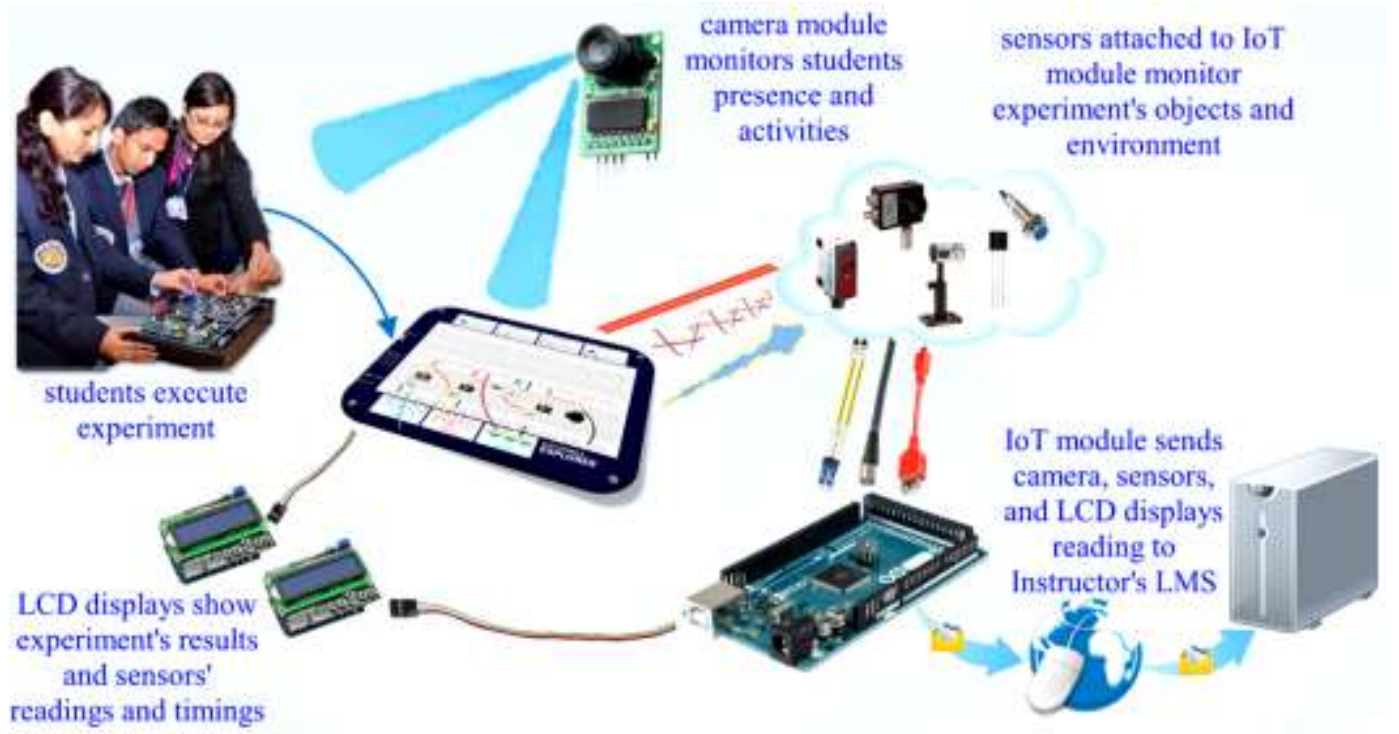

Figure 4. Evaluation of student performance in the laboratory [11]

\section{RESULTS}

After analyzing many related topics in terms of the effect of education development in terms of the use of advanced educational methods and linking them to the system, some lessons have been found from various publications. The educational process suffers from many restrictions imposed for both educator and learner in previous years. In the context of life development, various techniques are used to help develop and facilitate people's lives, such as the Internet service, which provides great services in all areas of life. In order to benefit from it in the field of education, the Internet of Things was used by connecting the campus to the Internet and via a private cloud. To facilitate students' access to the scientific topic and reduce the effort on staff as mentioned in the paper above. From this we see that the use of this service on campus has an 
effective impact on the educational process. It helps to raise the level of education on the campus that uses the Internet of Things feature and we thought that it is better for universities to link their campus within the systems.

\section{CONCLUSION}

Many of the problems and challenges have been solved in universities using advanced technology i.e. using the IoT, an example: keeping track of resources, construct smarter plans and develop access to information. The IoT has a great likely to give major values to education by motivating and engaging the staff and students and to fast learning. In this research, the usefulness of the internet of things was concluded by improving and developing education and the extent of their relevance sin universities and its application through the work of smart class using modern techniques in classrooms and using smart Laboratories to conduct experiments better and facilitate tests and use of devices to facilitate student communication with the teacher and other students and scientific material.

\section{REFERENCES}

[1] S. Gul, et al., "A survey on role of internet of things in education," IJCSNS, vol. 17, no. 5, p. 159, 2017.

[2] J. Gubbi, et al., "Internet of Things (IoT): A vision, architectural elements, and future directions," Future generation computer systems, vol. 29, no. 7, pp. 1645-1660, 2013.

[3] J. A. Stankovic, "Research directions for the internet of things," IEEE Internet of Things Journal, vol. 1, no. 1, pp. 3-9, 2014.

[4] J. Tan and S. G. Koo, "A survey of technologies in internet of things," in 2014 IEEE International Conference on Distributed Computing in Sensor Systems, pp. 269-274, May 2014.

[5] N. Bari, et al., "Internet of things as a methodological concept," in 2013 Fourth International Conference on Computing for Geospatial Research and Application, pp. 48-55, Jul 2013.

[6] L. Atzori, et al., "The internet of things: A survey," Computer networks, vol. 54, no. 15, pp. 2787-2805, 2010.

[7] M. Cata, "Smart University, a new concept in the Internet of Things," in 2015 14th RoEduNet International Conference-Networking in Education and Research (RoEduNet NER), pp. 195-197, 2015.

[8] H. F. Elyamany and A. H. Alkhairi, "IoT-academia architecture: A profound approach," IEEE/ACIS 16th Int. Conf. Softw. Eng. Artif. Intell. Netw. Parallel/Distributed Comput. SNPD 2015 - Proc., 2015.

[9] B. D. Ralhan, "How IoT is Transforming the Education Sector," Inc42, 2017. Available: https://inc42.com/resources/io-transforming-education/

[10] J. He, et al., "Integrating Internet of Things (IoT) into STEM undergraduate education: Case study of a modern technology infused courseware for embedded system course," in 2016 IEEE Frontiers in Education Conference (FIE), pp. 1-9, 2016.

[11] K. Mershad and P. Wakim, "A learning management system enhanced with internet of things applications," Journal of Education and Learning, vol. 7, no. 3, pp. 23, 2018.

[12] H. F. Hawari, et al., "Development of real time internet of things (IoT) based air quality monitoring system," Indonesian Journal of Electrical Engineering and Computer Science (IJEECS), vol. 13, no. 3, pp. 1039-1047, 2019.

[13] T. S. Gunawan, et al., "Prototype design of smart home system using internet of things," Indonesian Journal of Electrical Engineering and Computer Science, vol. 7, no. 1, pp. 107-115, 2017.

[14] Y. Lin and L. L. Zheng, "The Application of the Internet of Things in Education," Modern Educational Technology, vol. 2, no. 005, 2010.

[15] M. Mohanapriya, "IOT enabled Futurus Smart Campus with effective E-Learning: i-Campus," vol. 3, no. 4, pp. 81-87, 2016.

[16] J. Gómez, et al., "Interaction system based on internet of things as support for education," Procedia Computer Science, vol. 21, pp. 132-139, 2013.

[17] H. Zhiqiang and Z. Junming, "The Application of Internet of Things in Education and Its Trend of Development," Modern Distance Education Research, vol. 2, no. 19, 2011.

[18] M. Maksimović, "Transforming educational environment through Green Internet of Things (G-IoT)," Trend 2017, vol. 23, pp. 32-35, 2017.

[19] M. Moradi, K.R. Fard,“ An english-language teaching plan for children in the internet of things environment," Indonesian Journal of Electrical Engineering and Computer Science, vol. 13, no. 3, pp. 927-932., 2019

[20] H. Ning and S. Hu, "Technology classification, industry, and education for Future Internet of Things," International Journal of Communication Systems, vol. 25, no. 9, pp. 1230-1241, 2012.

[21] G. Kortuem, et al., "Educating the Internet-of-Things generation," Computer, vol. 46, no. 2, pp. 53-61, 2012.

[22] M. Bagheri and S. H. Movahed, "The effect of the Internet of Things (IoT) on education business model," in 2016 12th International Conference on Signal-Image Technology \& Internet-Based Systems (SITIS), pp. 435-441, 2016.

[23] M. Maksimović, "Iot Concept Application in Educational Sector Using Collaboration," Facta Universitatis, Series: Teaching, Learning and Teacher Education, vol. 1, no. 2, pp. 137-150, 2018.

[24] Z. Tianbo, "The internet of things promoting higher education revolution," in 2012 Fourth International Conference on Multimedia Information Networking and Security, pp. 790-793, 2012. 
[25] M. R. M. Veeramanickam and M. Mohanapriya, "IoT enabled Futurus Smart Campus with effective E-Learning: iCampus," GSTF Journal of Engineering Technology (JET), vol. 3, no. 4, 2017.

[26] Y. Yu, et al., "The exploration in the education of professionals in applied internet of things engineering," in 2010 4th International Conference on Distance Learning and Education, pp. 74-77, 2010.

[27] H. Aldowah, et al., "Internet of Things in Higher Education: A Study on Future Learning," Journal of Physics: Conference Series, vol. 892, no. 1, p. 012017, 2017.

[28] M. Selinger, et al., "Education and the Internet of Everything: How ubiquitous connectedness can help transform pedagogy," Cisco Consulting Services and Cisco EMEAR Education Team, 2013.

[29] A. Moubaiddin, et al., "Using Intelligent Agents in e-Learning," International Information Institute (Tokyo). Information, vol. 16, no. 10, pp. 7325-7342, 2013.

[30] L. I. RU-nian, "Study on the Internet of Things Based on RFID Technique," Journal of China academy of electronics and information technology, vol. 6, pp. 595-597, 2009.

[31] S. Charmonman, et al., "Applications of internet of things in e-learning," International Journal of the Computer, the Internet and Management, vol. 23, no. 3, pp. 1-4, 2015.

[32] N. Dlodlo, et al., "The State of Affairs in Internet of Things Research," CSIR Meraka Institute, Pretoria, South Africa in EJISE Journal, vol. 15, no. 3, 2012.

[33] G. Bautista and F. Borges, "Smart classrooms: Innovation in formal learning spaces to transform learning experiences," Bulletin of the IEEE technical Committee on learning Technology, vol. 15, no. 3, pp. 18-21, 2013.

[34] V. L. Uskov, et al., "The ontology of next generation smart classrooms," Smart Education and Smart e-Learning pp. 3-14, 2015.

[35] http://en.wikipedia.org/wiki/Classroom.

[36] A. Elsaadany and M. Soliman, "Experimental Evaluation of Internet of Things in the Educational Environment," International Journal of Engineering Pedagogy (iJEP), vol. 7, no. 3, pp. 50-60, 2017.

[37] N. Selwyn, "Social media in higher education," The Europa world of learning, vol. 1, pp. 1-10, 2012.

[38] M. Abdel-Basset, et al., "Internet of things in smart education environment: Supportive framework in the decision-making process," Concurrency and Computation: Practice and Experience, vol. 31, no. 10, p. e4515, 2019.

[39] G. Fortino, et al., "Agent-oriented cooperative smart objects: From IoT system design to implementation," IEEE Transactions on Systems, Man, and Cybernetics: Systems, vol. 99, pp. 1-18, 2017.

[40] W. Neil, et al., "End-to-End Sample Tracking in the Laboratory Using a Custom Internet of Things Device," SLAS TECHNOLOGY: Translating Life Sciences Innovation, vol. 23, no. 5, pp. 412-422, 2018.

[41] X. Nie, "Constructing smart campus based on the cloud computing platform and the internet of things," in Proceedings of the 2nd International Conference on Computer Science and Electronics Engineering, Atlantis Press, 2013.

[42] A. Sivanathan, et al., "Characterizing and classifying IoT traffic in smart cities and campuses," in 2017 IEEE Conference on Computer Communications Workshops (INFOCOM WKSHPS), pp. 559-564, 2017.

\section{BIOGRAPHIES OF AUTHORS}

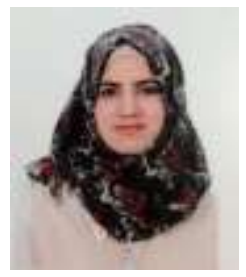

Ridhab Sami Abd-Ali received her first class B.Eng. degree in Computer Engineering in 2014 from University of Technology, Baghdad, Iraq. Then, she received her M.Sc. degree in Computer Engineering in 2017 from Babylon University of Technology, Baghdad, Iraq. Currently she is working at Al-Mustaqbal University College, Department of Computer Engineering Techniques, Iraq.

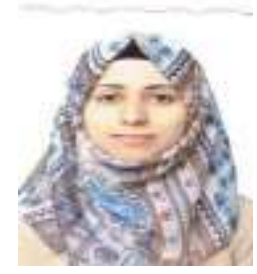

Sarah Abbas Radhi received her first class B.Eng. degree in Electrical Engineering in 2013 from Babylon University, Babil, Iraq. Then, she received her M.Sc. degree in Electrical/Elctronics and Communications Engineering in 2017 from Babylon University, Babil, Iraq. Currently she is working at Al-Mustaqbal University College, Department of Computer Engineering Techniques, Iraq.

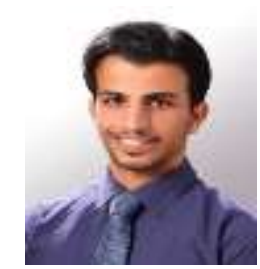

Zaid Ibrahim Rasool received his first class B.Eng. degree in Computer Scinece in 2010 from Al Mustansiriya University, Baghdad, Iraq. Then, he received her M.Sc. degree in Information Technology in 2017 from Middle East University, Amman, Jordan. Currently he is working at Al-Mustaqbal University College, Department of Computer Engineering Techniques, Iraq. 